Article

\title{
Minimum MOS Transistor Count Fractional-Order Voltage-Mode and Current-Mode Filters ${ }^{+}$
}

\author{
Panagiotis Bertsias 1(D), Costas Psychalinos 1,*(D), Ahmed S. Elwakil ${ }^{2,3}\left(\mathbb{D}\right.$ and Brent Maundy ${ }^{3}$ (1) \\ 1 Electronics Laboratory, Department of Physics, University of Patras, GR-26504 Rio Patras, Greece; \\ panosber@upatras.gr \\ 2 Department of Electrical and Computer Engineering, University of Sharjah, 27272 Sharjah, UAE; \\ elwakil@ieee.org \\ 3 Department of Electrical and Computer Engineering, University of Calgary, Calgary, AB T2N 1N4, Canada; \\ bmaundy@ucalgary.ca \\ * Correspondence: cpsychal@upatras.gr \\ + This paper is an extended version of our paper published in 8th International Conference on Modern \\ Circuits and Systems Technologies (MOCAST), Thessaloniki, Greece, 13-15 May 2019.
}

Received: 23 November 2019; Accepted: 4 December 2019; Published: 6 December 2019

\begin{abstract}
Voltage-mode and current-mode fractional-order filter topologies, which are capable of realizing various types of transfer functions, are introduced in this paper. Thanks to the employment of the transconductance parameter of the MOS transistors, the derived filter structures offer the benefit of the electronic adjustment of their frequency characteristics. With regards to the literature, the number of MOS transisitors is minimized leading to significant reduction of the circuit complexity and power dissipation. Simulation results, derived using the Design Kit of the $0.35 \mu \mathrm{m}$ Austria Mikro Systeme CMOS process and the Cadence IC design suite, confirm the correct operation of the presented filter structures.
\end{abstract}

Keywords: CMOS analog integrated circuits; filters; fractional-order circuits; fractional-order filters; voltage-mode filters; current-mode filters

\section{Introduction}

Owing to the interdisciplinary nature of fractional-order calculus [1-3], the development of fractional-order filters has gained a significant research interest because of the offered more precise gradient of the transition from pass-band to stop-band, with regards to their integer-order counterparts. This originates from the fact that the slope of the attenuation of an $n+\alpha$ order filter, with $n$ integer and $0<\alpha<1$, is equal to $-6 \cdot(n+\alpha) \mathrm{dB} /$ Oct., instead of $-6 \cdot n \mathrm{~dB} /$ Oct. slope realized by the corresponding integer-order filters [4]. Another benefit of the fractional-order filters is their capability of performing scaling of the realized time-constants due to their dependence on the order of the filter. This is a very attractive feature in the case of biomedical applications, where very large values of time-constants are required [5].

Due to the absence of commercially available fractional-order capacitors [6-8], fractional-order filters can be derived through: (a) the substitution of the conventional (i.e., integer-order) capacitors in the well-known integer-order filters with RC networks (e.g., Foster or Cauer) [9,10], and (b) the implementation of the rational integer-order transfer functions, which are derived through the substitution of the Laplacian fractional-order operator with a suitable expression offered by approximation formulas such as Oustaloup, Continued Fraction Expansion, Matsuda, El-Khazali etc. [11-16]. Comparing the aforementioned methods, the main derivation is that the first one offers a quick design procedure but the resulting filter structures suffer from the absence of electronic tuning 
of the employed RC networks; the second one offers fully electronic tunability of the characteristics of the fractional-order filters. On the other hand, the active component count is much higher in this case and, consequently, the circuit complexity and the power dissipation are both increased [5].

Fractional-order filters, implemented using various types of active elements such as Operational Amplifiers (op-amps), Operational Transconductance Amplifiers (OTAs), second generation Current Conveyors (CCIIs), Current-Feedback Operational Amplifiers (CFOAs) and current-mirrors (CMs), have been already proposed in the literature [17-36]. All of them suffer from the increased number of MOS transistors which are required for implementing the active elements. In addition, only the filter realizations performed with OTAs or CMs offer the benefit of the electronic adjustment of the frequency characteristics, due to the employment of the transconductance parameter $\left(g_{m}\right)$ of the MOS transistors.

The contribution made in this work is the introduction of fractional-order voltage-mode and current-mode filter topologies, constructed from a minimum number of MOS transistors with regards to those required in the already published topologies. The proposed structures are capable of providing low-pass, high-pass, and band-pass filter functions and, consequently, they are multi-function schemes being attractive due to their design versatility and flexibility. Due to the realization of time-constants through the employment of the electronically controlled transconductance parameter, their characteristic frequencies can be electronically adjusted by the corresponding dc bias currents.

The paper is organized as follows: a short introduction on the fractional-order filter characteristics is given in Section 2, while the proposed implementations are presented in Section 3. Their performance evaluation is provided in Section 4, through simulation results obtained using the Cadence IC design suite and the MOS transistor parameters provided by the Austrian Mikro Systeme (AMS) CMOS $0.35 \mu \mathrm{m}$ Design Kit.

\section{Fractional-Order Filters}

The transfer function of a fractional low-pass filter of order $0<\alpha<1$ is

$$
H_{l p}(s)=\frac{1}{\left(\tau_{\alpha} s\right)^{\alpha}+1},
$$

with variable $\tau_{\alpha}$ being the time-constant, associated to the pole frequency $\left(\omega_{0}\right)$ through the relationship: $\omega_{0}=1 / \tau_{\alpha}[31]$.

Setting $s^{\alpha}=\omega^{\alpha}[\cos (0.5 \alpha \pi)+j \sin (0.5 \alpha \pi)]$ in (1), the expressions of the gain and phase responses are given by (2) and (3), respectively

$$
\begin{aligned}
\left|H_{l p}(j \omega)\right| & =\frac{1}{\sqrt{\left(\frac{\omega}{\omega_{0}}\right)^{2 \alpha}+2\left(\frac{\omega}{\omega_{0}}\right)^{\alpha} \cos \left(\frac{\alpha \pi}{2}\right)+1}}, \\
\angle H_{l p}(j \omega) & =-\tan ^{-1}\left(\frac{\left(\frac{\omega}{\omega_{0}}\right)^{\alpha} \sin \left(\frac{\alpha \pi}{2}\right)}{\left(\frac{\omega}{\omega_{0}}\right)^{\alpha} \cos \left(\frac{\alpha \pi}{2}\right)+1}\right) .
\end{aligned}
$$

The maximum gain of the filter is equal to 1 for $\omega \rightarrow 0$, while the slope of the stop-band attenuation is equal to $-6 \cdot \alpha \mathrm{dB} /$ Oct. Defining as half-power frequency $\left(\omega_{h, l p}\right)$ the frequency where a $3 \mathrm{~dB}$ drop from the maximum gain is observed, the expressions of this frequency as well as of the phase at this frequency, derived from (2) and (3), are provided by the Equations (4) and (5), respectively

$$
\omega_{h, l p}=\omega_{0}\left[\sqrt{1+\cos ^{2}\left(\frac{\alpha \pi}{2}\right)}-\cos \left(\frac{\alpha \pi}{2}\right)\right]^{1 / \alpha},
$$




$$
\angle H_{l p}\left(\omega_{h, l p}\right)=-\tan ^{-1}\left[\frac{\sin \left(\frac{\alpha \pi}{2}\right)}{2 \cos \left(\frac{\alpha \pi}{2}\right)+\sqrt{1+\cos ^{2}\left(\frac{\alpha \pi}{2}\right)}}\right] .
$$

According to (4), the pole frequency is different from the half-power frequency and not equal, as in the case of conventional integer-order filters. As the half-power frequency depends on the order of the filter, scaling of the time-constant is possible by adjusting the order of the filter. For example, this is very useful in biomedical applications where extremely small cut-off frequencies are required.

A fractional high-pass filter of order $0<\alpha<1$ is described by the the transfer function in (6)

$$
H_{h p}(s)=\frac{\left(\tau_{\alpha} s\right)^{\alpha}}{\left(\tau_{\alpha} s\right)^{\alpha}+1} .
$$

The expressions of the magnitude and phase responses are

$$
\begin{gathered}
\left|H_{h p}(j \omega)\right|=\frac{\left(\frac{\omega}{\omega_{0}}\right)^{\alpha}}{\sqrt{\left(\frac{\omega}{\omega_{0}}\right)^{2 \alpha}+2\left(\frac{\omega}{\omega_{0}}\right)^{\alpha} \cos \left(\frac{\alpha \pi}{2}\right)+1}}, \\
\angle H_{h p}(j \omega)=\frac{\alpha \pi}{2}-\tan ^{-1}\left(\frac{\left(\frac{\omega}{\omega_{0}}\right)^{\alpha} \sin \left(\frac{\alpha \pi}{2}\right)}{\left(\frac{\omega}{\omega_{0}}\right)^{\alpha} \cos \left(\frac{\alpha \pi}{2}\right)+1}\right) .
\end{gathered}
$$

The maximum gain of the filter is equal to 1 for $\omega \rightarrow \infty$, while the slope of the gradient from stop-band to pass-band is equal to $+6 \cdot \alpha \mathrm{dB} /$ Oct.

The half-power frequency $\left(\omega_{h, h p}\right)$ is given by the expression in (9)

$$
\omega_{h, h p}=\omega_{0}\left[\sqrt{1+\cos ^{2}\left(\frac{\alpha \pi}{2}\right)}+\cos \left(\frac{\alpha \pi}{2}\right)\right]^{1 / \alpha}
$$

and the observations made in the case of the low-pass filter, about the dependence of the half-power frequency on the order, are still valid. The phase at this frequency is given by (10)

$$
\angle H_{h p}\left(\omega_{h, h p}\right)=\frac{\alpha \pi}{2}-\tan ^{-1}\left[\frac{\sin \left(\frac{\alpha \pi}{2}\right)}{\sqrt{1+\cos ^{2}\left(\frac{\alpha \pi}{2}\right)}}\right] .
$$

A fractional-order band-pass filter is described by the transfer function

$$
H_{b p}(s)=\frac{K_{4} s^{\alpha}}{s^{\alpha+\beta}+K_{1} s^{\alpha}+K_{2} s^{\beta}+K_{3}},
$$

where the order of the band-pass filter is equal to $\alpha+\beta$. The slope of the gradient at low frequencies is $+6 \cdot \alpha \mathrm{dB} /$ Oct., while at high-frequencies the slope becomes $-6 \cdot \beta \mathrm{dB} /$ Oct., giving the capability of implementing asymmetric band-pass filters with controlled slopes in both low and high frequency ranges.

The peak frequency of the band-pass filter $\left(\omega_{\text {peak }}\right)$ is calculated through the condition: $d / d \omega \mid$ $H_{b p}\left(\omega_{\text {peak }}\right) \mid=0$, while the lower $\left(\omega_{\text {low }}\right)$ and upper $\left(\omega_{\text {high }}\right)$ cut-off frequencies are calculated by setting: 0.707. $\left|H_{b p}\left(\omega_{\text {peak }}\right)\right|=\left|H_{b p}\left(\omega_{\text {low }(\text { high })}\right)\right|$. Moreover, the realized quality factor $(Q)$ is given by the formula: $Q=\omega_{\text {peak }} /\left(\omega_{\text {high }}-\omega_{\text {low }}\right)[36]$. 


\section{Proposed Implementations}

\subsection{Voltage-Mode Filters}

As it was mentioned in Section 1, OTA-C implementations are attractive due to the offered electronic tuning which originates from the control of the transconductance parameter by the associated bias current [37]. Considering that the impedance of a fractional-order $(0<\alpha<1)$ capacitor is given by (12)

$$
Z(s)=\frac{1}{C_{\alpha} S^{\alpha}}
$$

with $C_{\alpha}$ being the pseudo-capacitance expressed in Farad/ $\sec ^{1-\alpha}$, and that the transconductance of OTAs is $g_{m}$, then the OTA-C filters depicted in Figure 1a,b implement the transfer functions in (1) and (6), respectively. The realized time-constant is given by the formula: $\tau_{\alpha}=\left(C_{\alpha} / g_{m}\right)^{1 / \alpha}$.

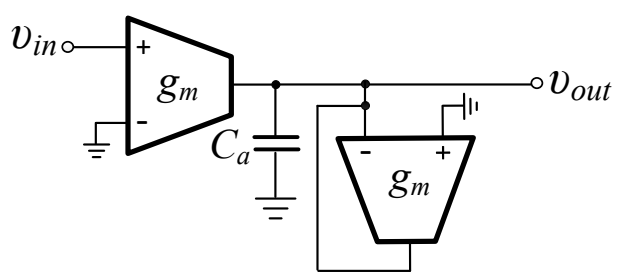

(a)

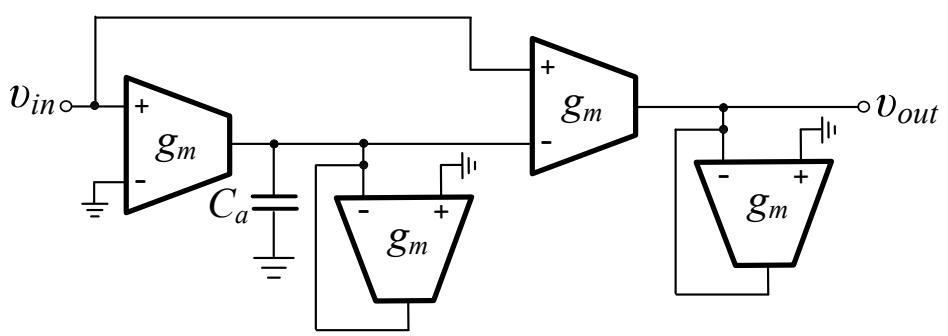

(b)

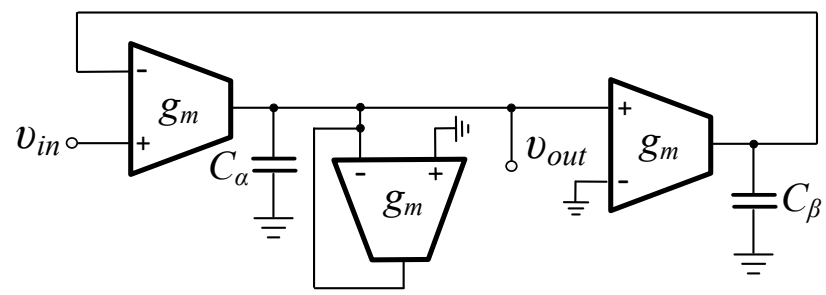

(c)

Figure 1. Realization of voltage-mode fractional-order (a) low-pass, (b) high-pass, and (c) band-pass filters using OTAs as active elements.

The two-integrator loop OTA-C filter in Figure 1c implements the following band-pass filter function

$$
H_{b p}(s)=\frac{\left(\frac{1}{\tau_{\alpha}^{\alpha}}\right) s^{\alpha}}{s^{\alpha+\beta}+\left(\frac{1}{\tau_{\alpha}^{\alpha}}\right) s^{\alpha}+\frac{1}{\tau_{\alpha}^{\alpha} \tau_{\beta}^{\beta}}},
$$

with the time-constant $\tau_{\beta}$ given by the formula: $\tau_{\beta}=\left(C_{\beta} / g_{m}\right)^{1 / \beta}$. 
In order to reduce the MOS transistor count, the proposed topology is demonstrated in Figure 2a [38]. Considering that transistors Mp1-Mp2 are matched, with transconductance parameter equal to $g_{m p}$, the derived transfer functions are:

$$
\begin{gathered}
H_{l p}(s)=\frac{1}{\left[\left(C_{\alpha} / g_{m p}\right)^{1 / \alpha} s\right]^{\alpha}+1}, \\
H_{h p}(s)=-\frac{\left[\left(C_{\alpha} / g_{m p}\right)^{1 / \alpha} s\right]^{\alpha}}{\left[\left(C_{\alpha} / g_{m p}\right)^{1 / \alpha} s\right]^{\alpha}+1} .
\end{gathered}
$$

Comparing (1) with (14) and (6) with (15), it is readily observed that the topology in Figure 2a implements low-pass and high-pass filter functions, with the time-constant given by (16)

$$
\tau_{\alpha}=\left(\frac{C_{\alpha}}{g_{m p}}\right)^{1 / \alpha}
$$

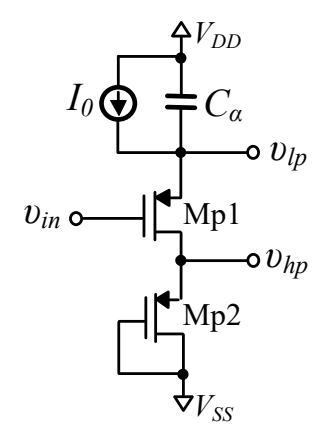

(a)

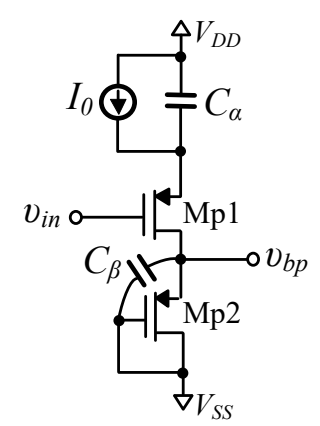

(b)

Figure 2. Proposed voltage-mode fractional-order (a) low-pass and high-pass, and (b) band-pass filter topologies.

Adding a fractional-order capacitor $C_{\beta}(0<\beta<1)$ in the topology in Figure $2 \mathrm{a}$, as it is depicted in Figure $2 b$, the topology implements the following band-pass filter function

$$
H_{b p}(s)=-\frac{\left(\frac{1}{\tau_{\beta}^{\beta}}\right) s^{\alpha}}{s^{\alpha+\beta}+\left(\frac{1}{\tau_{\beta}^{\beta}}\right) s^{\alpha}+\left(\frac{1}{\tau_{\alpha}^{\alpha}}\right) s^{\beta}+\frac{1}{\tau_{\alpha}^{\alpha} \tau_{\beta}^{\beta}}},
$$


with $\tau_{\alpha}$ and $\tau_{\beta}$ given by (16) and (18), respectively,

$$
\tau_{\beta}=\left(\frac{C_{\beta}}{g_{m p}}\right)^{1 / \beta} .
$$

Comparing (17) with (11) the derived design equations are: $K_{1}=K_{4}=1 / \tau_{\beta}^{\beta}, K_{2}=1 / \tau_{\alpha}^{\alpha}$, and $K_{3}=1 / \tau_{\alpha}^{\alpha} \tau_{\beta}^{\beta}$.

\subsection{Current-Mode Filters}

The implementation of current-mode low-pass and high-pass filters, using OTAs as active elements, is demonstrated in Figure $3 a, b$, where the topologies implement the transfer functions in (14) and (15), respectively. The implementation of the band-pass filter is performed by the topology in Figure 3c, which realizes the transfer function in (13).

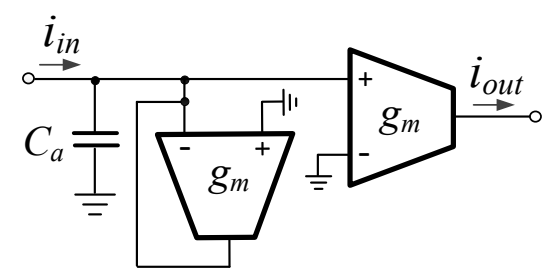

(a)

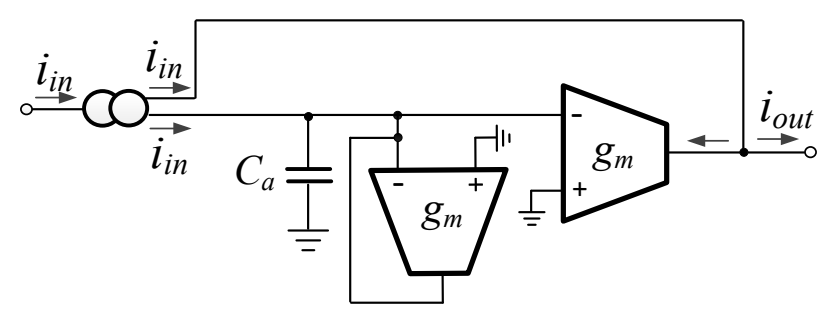

(b)

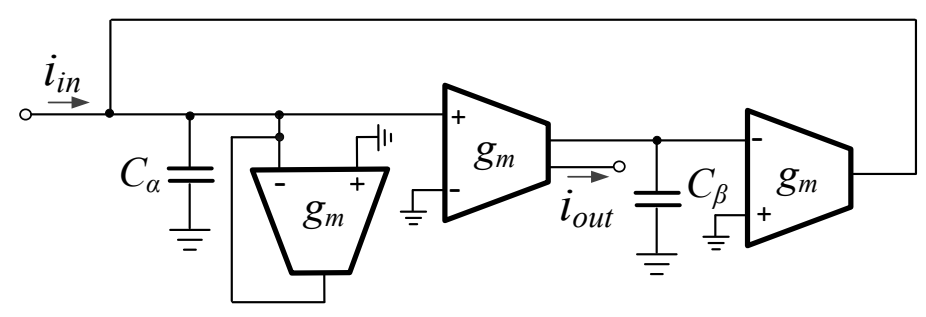

(c)

Figure 3. Realization of current-mode fractional-order (a) low-pass, (b) high-pass, and (c) band-pass filters using OTAs as active elements.

The proposed current-mode low-pass filter structure is depicted in Figure 4a. Applying the Kirchhoff's current law (KCL) at the input terminal and taking into account the current-mirror operation, implemented by transistors Mn1-Mn2, it is derived that

$$
i_{\text {in }}=i_{\text {out }}+i_{c \alpha}
$$

with $i_{c \alpha}$ being the current that flows through the capacitor $C_{\alpha}$, given by the formula

$$
i_{c \alpha}=v_{c \alpha} C_{\alpha} s^{\alpha} .
$$


Considering that $g_{m n}$ is the transconductance of Mn1-Mn2, the output current is expressed as

$$
i_{o u t}=g_{m n} v_{c \alpha}
$$

Using (19)-(21) it is derived that the topology in Figure 4a implements the transfer function in (14) with a time-constant given by (22)

$$
\tau_{\alpha}=\left(\frac{C_{\alpha}}{g_{m n}}\right)^{1 / \alpha} .
$$

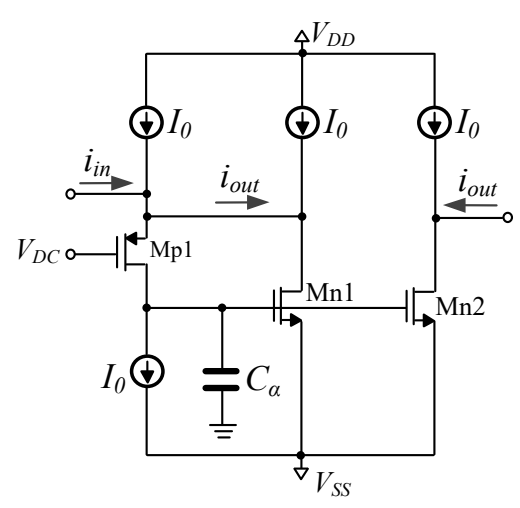

(a)

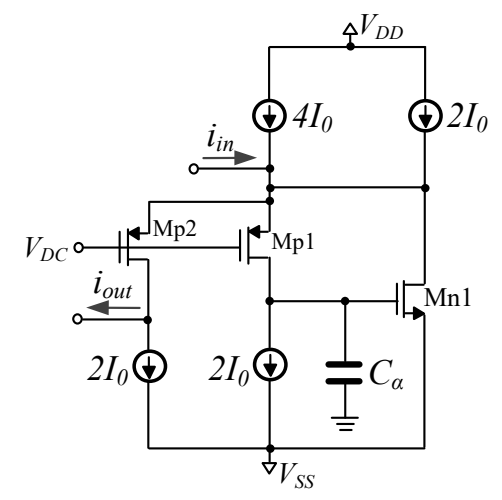

(b)

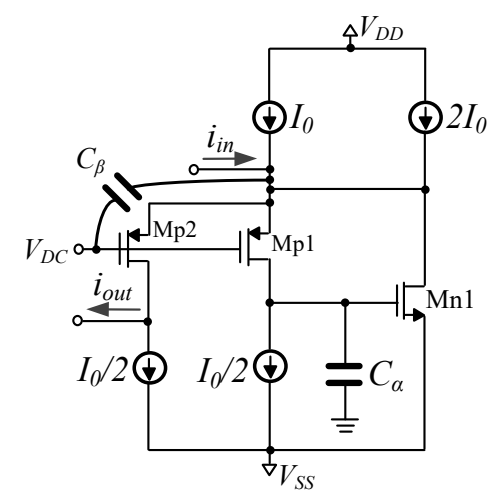

(c)

Figure 4. Proposed current-mode fractional-order (a) low-pass, (b) high-pass, and (c) band-pass filters. 
Let us consider the topology in Figure 4b; applying the KCL at the input terminal and assuming that Mp1-Mp2 are matched transistors forming a current-mirror with $a c$ current equal to $i_{o u t}$, it is obtained that

$$
i_{\text {in }}=g_{m n} v_{c \alpha}+2 i_{o u t} .
$$

In addition, the current that flows through the capacitor $C_{\alpha}$ is

$$
i_{c \alpha}=i_{o u t}=v_{c \alpha} C_{\alpha} s^{\alpha} .
$$

Using Equations (23) and (24) the derived transfer function is

$$
H_{h p}(s)=0.5 \cdot \frac{\left[\left(C_{\alpha} / g_{m n}\right)^{1 / \alpha} s\right]^{\alpha}}{\left[\left(C_{\alpha} / g_{m n}\right)^{1 / \alpha} s\right]^{\alpha}+1} .
$$

Inspecting (25) it is readily obtained that the topology in Figure $4 \mathrm{~b}$ implements a high-pass filter function with the time-constant given by (22).

The topology in Figure $4 \mathrm{c}$ is derived by adding an extra fractional-order capacitor $\left(C_{\beta}\right)$ in the topology of Figure $4 \mathrm{~b}$. The KCL at the input node takes the form

$$
i_{\text {in }}=g_{m n} v_{c \alpha}+i_{c \beta}+2 i_{o u t} .
$$

The current that flows through the capacitor $C_{\alpha}$ is still given by (24), while for the capacitor $C_{\beta}$ the following expression is valid

$$
i_{\text {out }}=g_{m p} v_{c \beta}=\frac{g_{m p} i_{c \beta}}{C_{\beta} s^{\beta}} .
$$

Using Equations (24), (26) and (27), the derived transfer function is

$$
H_{b p}(s)=0.5 \cdot \frac{\left(\frac{1}{\tau_{\beta}^{\beta}}\right) s^{\alpha}}{s^{\alpha+\beta}+\left(\frac{1}{\tau_{\beta}^{\beta}}\right) s^{\alpha}+\frac{1}{\tau_{\alpha}^{\alpha} \tau_{\beta}^{\beta}}},
$$

with the time-constant $\tau_{\alpha}$ given by (22) and the time-constant $\tau_{\beta}$ given by (18).

\section{Simulation and Comparison Results}

The behavior of the proposed topologies will be evaluated using the Cadence IC design suite and the Design Kit provided by the AMS $0.35 \mu \mathrm{m}$ CMOS process. The power supply voltages were $V_{D D}=-V_{S S}=0.5 \mathrm{~V}$. Considering the fourth-order Foster-II network given in Figure 5 and using the Continued Fraction Expansion approximation with center frequency $10 \mathrm{~Hz}$ and the Matlab code introduced in [39], then the values of the passive element values of the RC network for approximating fractional-order capacitances $\left(C_{\alpha}\right)$ of orders $\{0.3,0.5,0.7\}$ with values $85.4 \mathrm{nF} / \mathrm{sec}^{0.7}, 37.4 \mathrm{nF} / \mathrm{sec}^{0.5}$, and $16.3 \mathrm{nF} / \mathrm{sec}^{0.3}$, are provided in Table 1 .

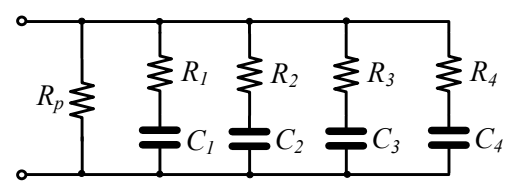

Figure 5. RC network for approximating the fractional-order capacitors in the proposed fractional-order filter topologies. 
Table 1. Values of passive elements of the network in Figure 5.

\begin{tabular}{cccc}
\hline Element & $\mathbf{8 5 . 4} \mathbf{~ n F} / \mathbf{s e c}^{\mathbf{0 . 7}}$ & $\mathbf{3 7 . 4} \mathbf{~ n F} / \mathbf{s e c}^{\mathbf{0 . 5}}$ & $\mathbf{1 6 . 3} \mathbf{~ n F} / \mathbf{s e c}^{\mathbf{0 . 3}}$ \\
\hline$R_{p}$ & $12 \mathrm{M} \Omega$ & $30 \mathrm{M} \Omega$ & $90 \mathrm{M} \Omega$ \\
$R_{1}$ & $1.6 \mathrm{M} \Omega$ & $457.7 \mathrm{k} \Omega$ & $133.1 \mathrm{k} \Omega$ \\
$R_{2}$ & $6.4 \mathrm{M} \Omega$ & $3.8 \mathrm{M} \Omega$ & $3.2 \mathrm{M} \Omega$ \\
$R_{3}$ & $10.6 \mathrm{M} \Omega$ & $8.9 \mathrm{M} \Omega$ & $10.8 \mathrm{M} \Omega$ \\
$R_{4}$ & $11 \mathrm{M} \Omega$ & $13.4 \mathrm{M} \Omega$ & $23.1 \mathrm{M} \Omega$ \\
$C_{1}$ & $472 \mathrm{pF}$ & $1.1 \mathrm{nF}$ & $2.1 \mathrm{nF}$ \\
$C_{2}$ & $972.3 \mathrm{pF}$ & $1.4 \mathrm{nF}$ & $1.4 \mathrm{nF}$ \\
$C_{3}$ & $2.4 \mathrm{nF}$ & $2.5 \mathrm{nF}$ & $1.8 \mathrm{nF}$ \\
$C_{4}$ & $13.5 \mathrm{nF}$ & $9 \mathrm{nF}$ & $4.3 \mathrm{nF}$ \\
\hline
\end{tabular}

Considering MOS transistors biased in the sub-threshold region, their transconductance is given by (29)

$$
g_{m}=\frac{I_{0}}{n V_{T}},
$$

where $1<n<2$ is the sub-threshold slope factor of a MOS transistor, $V_{T}$ is the thermal voltage ( $26 \mathrm{mV} @ 27^{\circ} \mathrm{C}$ ), and $I_{0}$ is the bias current $[40,41]$. Thus, the realized-time constants are electronically adjusted, offering the capability of electronic adjustment of the frequency characteristics of the realized filter functions.

\subsection{Voltage-Mode Filters}

Assuming a dc bias current equal to $I_{0}=10 \mathrm{nA}$, the aspect ratio of Mp1-Mp2 in Figure 2 was chosen to be $100 \mu \mathrm{m} / 1 \mu \mathrm{m}$, in order to guarantee operation in the sub-threshold region.

The obtained frequency magnitude and phase responses of the low-pass and high-pass filters are provided in Figure 6, while the corresponding theoretically predicted plots are given by dashes. The most important performance characteristics are given in Tables 2 and 3, along with the theoretical values given between parentheses.

Table 2. Frequency characteristics of the low-pass filter in Figure 2a.

\begin{tabular}{cccc}
\hline Parameter & $\boldsymbol{\alpha}=\mathbf{0 . 3}$ & $\boldsymbol{\alpha}=\mathbf{0 . 5}$ & $\boldsymbol{\alpha}=\mathbf{0 . 7}$ \\
\hline$f_{h, l p}(\mathrm{~Hz})$ & $0.76(0.7)$ & $2.6(2.7)$ & $5.2(5.3)$ \\
phase @ $f_{h, l p}(\mathrm{deg})$ & $-8.5(-8.3)$ & $-14.8(-15)$ & $-24(-23.9)$ \\
slope (dB/Oct.) & $-1.6(-1.8)$ & $-2.8(-3)$ & $-4(-4.2)$ \\
\hline
\end{tabular}

Table 3. Frequency characteristics of the high-pass filter in Figure 2a.

\begin{tabular}{cccc}
\hline Parameter & $\boldsymbol{\alpha}=\mathbf{0 . 3}$ & $\boldsymbol{\alpha}=\mathbf{0 . 5}$ & $\boldsymbol{\alpha}=\mathbf{0 . 7}$ \\
\hline$f_{h, h p}(\mathrm{~Hz})$ & $142(145)$ & $38(37.3)$ & $18(18.7)$ \\
phase @ $f_{h, h p}(\mathrm{deg})$ & $-172(-172)$ & $-165(-165)$ & $-156(-156)$ \\
slope $(\mathrm{dB} /$ Oct.) & $1.5(1.8)$ & $2.7(3)$ & $3.9(4.2)$ \\
\hline
\end{tabular}

The electronic tuning capability of the filter structure in Figure 2a has been evaluated by considering the set of bias currents $\{5,10,15\} \mathrm{nA}$. The obtained frequency responses are depicted in Figure 7, where the values of the half-power frequency were $\{0.75,2.6,5.8\} \mathrm{Hz}$ for the low-pass filter and $\{9.5,38,82\} \mathrm{Hz}$ for the high-pass filter.

According to (4), (9), (16) and (29), the half-power frequencies $\omega_{h}^{\prime}$ and $\omega_{h}$, which correspond to bias currents $I_{0}^{\prime}$ and $I_{0}$, are related according to the expression given by (30)

$$
\frac{\omega_{h}^{\prime}}{\omega_{h}}=\left(\frac{I_{0}^{\prime}}{I_{0}}\right)^{1 / \alpha}
$$


Therefore, the theoretically predicted values will be $\{0.68,2.7,6.1\} \mathrm{Hz}$ and $\{9.3,37.3,83.9\} \mathrm{Hz}$, respectively, confirming the aforementioned feature.

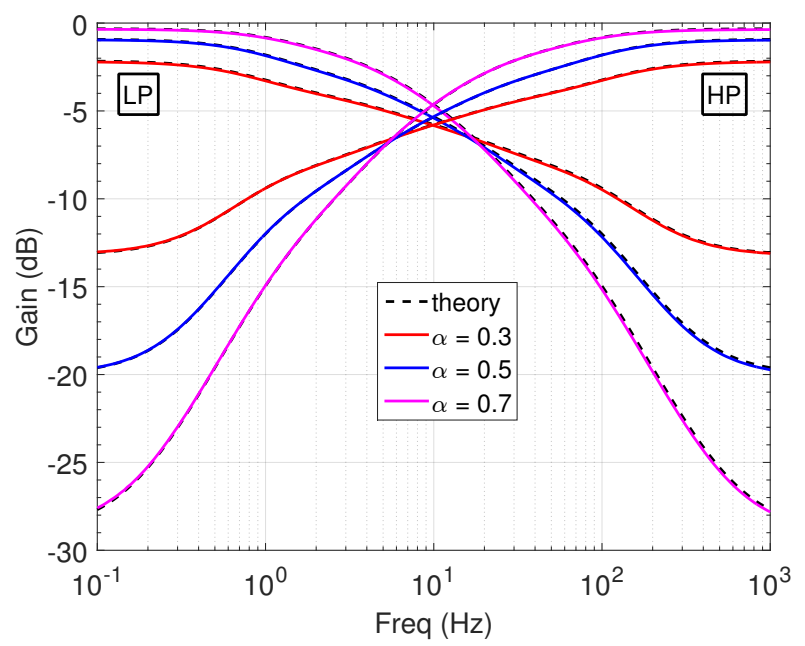

(a)

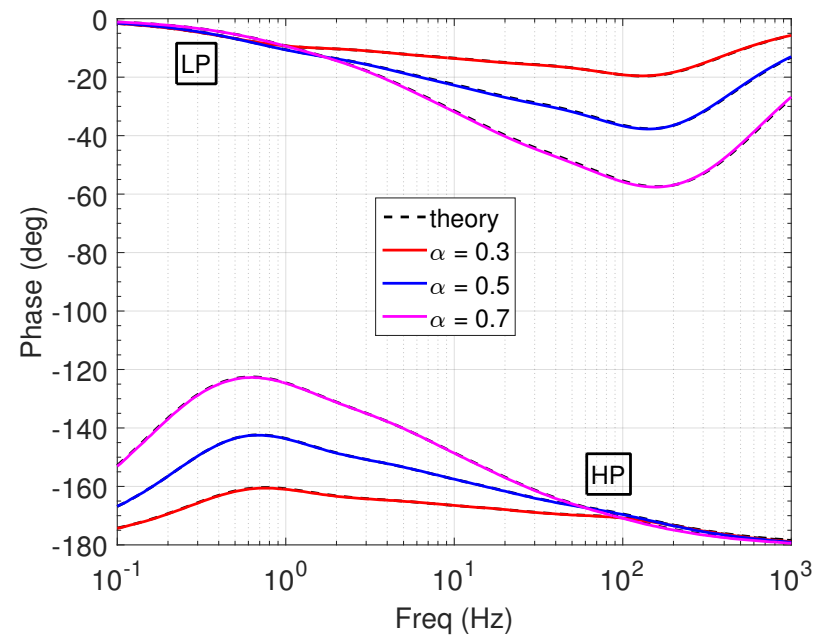

(b)

Figure 6. Simulated frequency responses of the proposed voltage-mode low-pass and high-pass filters in Figure 2a (a) gain, and (b) phase.

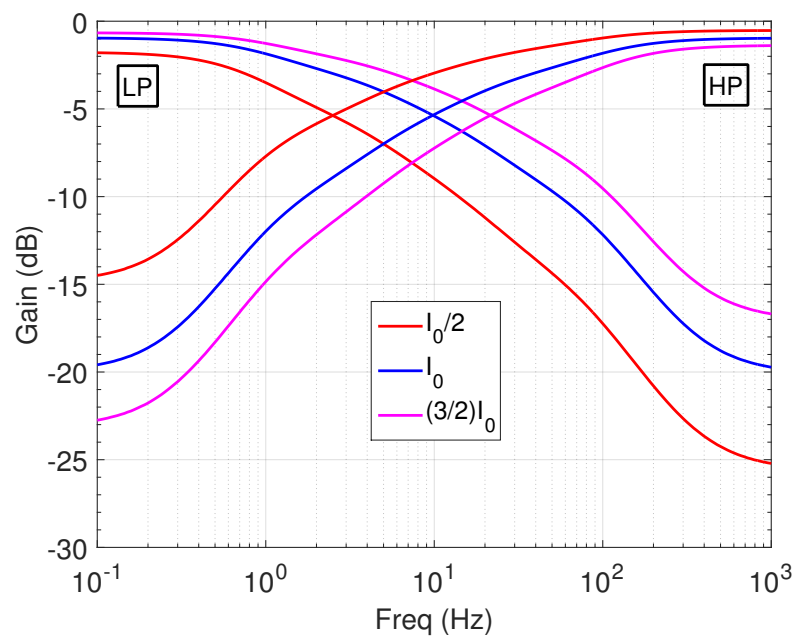

Figure 7. Demonstration of the electronic tuning capability of the filter structure in Figure 2a. 
The effects of MOS transistor parameters mismatch, as well as those of the process parameter variations, have been evaluated using the Monte Carlo analysis tool ( $N=100$ runs) offered by the Analog Design Environment of the Cadence software. The derived statistical plots for order $\alpha=0.5$ are provided in Figure 8, while the values of standard deviation of the half-power frequency were $\{0.03,0.01,0.01\} \mathrm{Hz}$ for the low-pass filter and $\{0.5,0.16,0.03\} \mathrm{Hz}$ for the high-pass filter, confirming that the proposed structure has reasonable sensitivity characteristics.

In order to estimate which circuit element contributes to the maximum error, a sensitivity analysis has been performed through the Cadence software. According to this analysis, it is derived that the deviations in the measurement of the half-power frequency as well as of the maximum gain in both low-pass and high-pass filter topologies of Figure 2a, are caused by transistor Mp1.

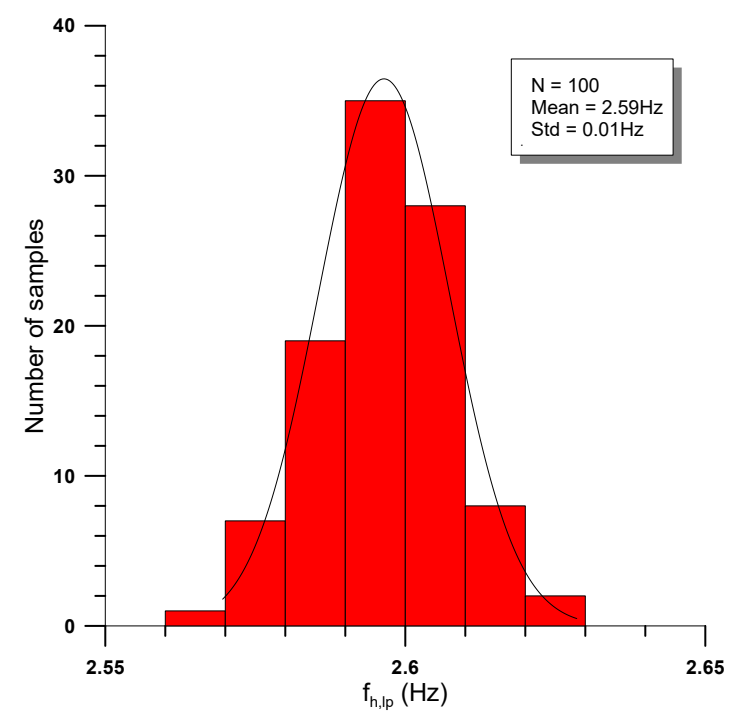

(a)

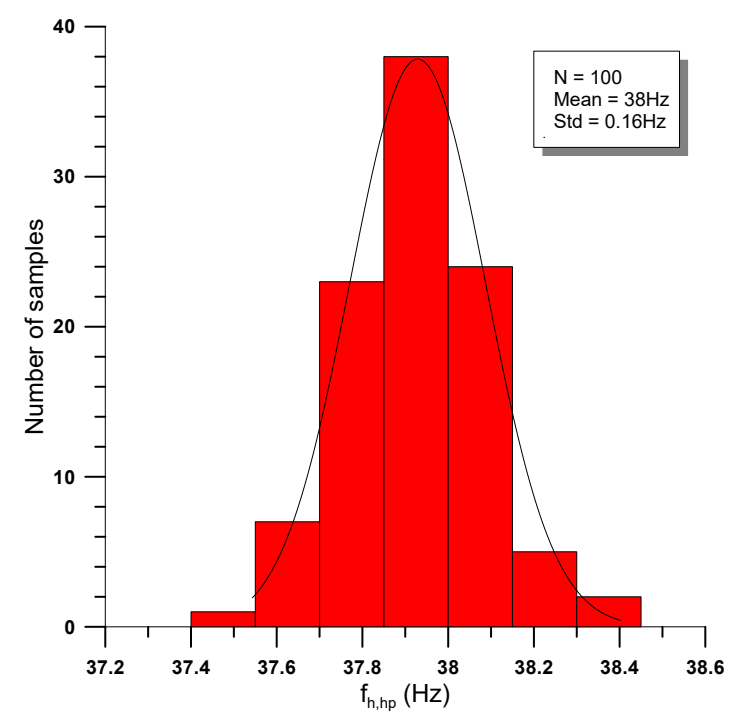

(b)

Figure 8. Statistical plots about the sensitivity of the half-power frequency in the case of the voltage-mode (a) low-pass, and (b) high-pass filters of order $\alpha=0.5$.

The evaluation of the performance of the band-pass filter in Figure $2 \mathrm{~b}$ has been performed by considering that the orders $(\alpha, \beta)$ are $\{(0.5,0.7),(0.5,0.5),(1,0.5)\}$. The derived frequency responses are depicted in Figure 9, while the results in Table 4 confirm the correct operation of the filter. 
Table 4. Frequency characteristics of the band-pass filter in Figure $2 b$.

\begin{tabular}{cccc}
\hline Parameter & $(\mathbf{0 . 5}, \mathbf{0 . 7})$ & $(\mathbf{0 . 5}, \mathbf{0 . 5})$ & $(\mathbf{1}, \mathbf{0 . 5})$ \\
\hline$f_{\text {peak }}(\mathrm{Hz})$ & $6.6(6.6)$ & $10(10)$ & $16(16.2)$ \\
gain@ $f_{\text {peak }}(\mathrm{dB})$ & $-9.8(-9.8)$ & $-10.7(-10.7)$ & $-7.9(-7.8)$ \\
$f_{\text {low }}(\mathrm{Hz})$ & $1(1)$ & $1(1)$ & $5(5.2)$ \\
$f_{\text {high }}(\mathrm{Hz})$ & $36.3(37)$ & $93(96)$ & $72(70)$ \\
\hline
\end{tabular}

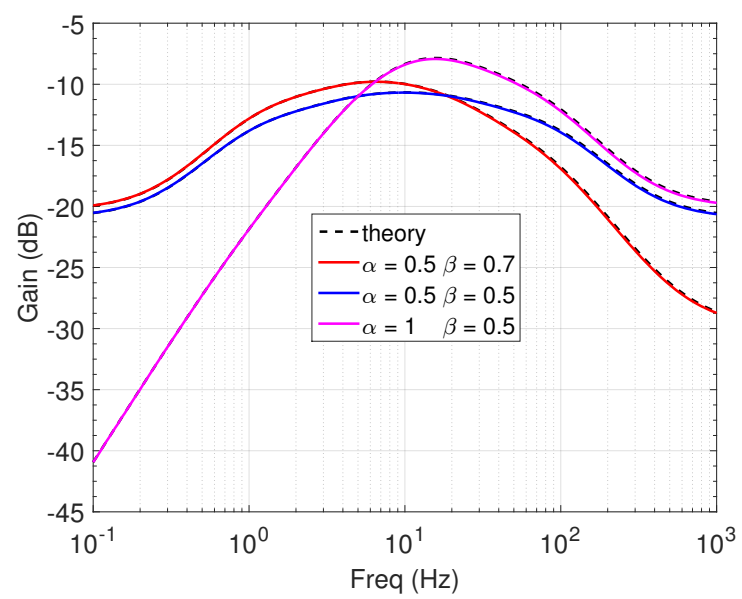

Figure 9. Frequency responses of the band-pass filter in Figure $2 b$ for various orders.

\subsection{Current-Mode Filters}

The power supply voltages and capacitor values which will be considered in the performance evaluation of the current-mode filters will be the same as in the case of the voltage-mode filters. In addition, the value of the dc voltage $V_{D C}$ will be equal to $150 \mathrm{mV}$.

The frequency responses of the current-mode low-pass (Figure 4a) and high-pass (Figure 4b) filters are provided in Figure 10. The results in Tables 5 and 6, where the theoretically predicted values are given between parentheses, confirm the accurate operation of the proposed filters.

Table 5. Frequency characteristics of the low-pass filter in Figure 4a.

\begin{tabular}{cccc}
\hline Parameter & $\boldsymbol{\alpha}=\mathbf{0 . 3}$ & $\boldsymbol{\alpha}=\mathbf{0 . 5}$ & $\boldsymbol{\alpha}=\mathbf{0 . 7}$ \\
\hline$f_{h, l p}(\mathrm{~Hz})$ & $0.76(0.7)$ & $2.6(2.7)$ & $5.2(5.3)$ \\
phase @ $f_{h, l p}(\mathrm{deg})$ & $-8.5(-8.3)$ & $-14.8(-15)$ & $-24(-23.9)$ \\
slope $(\mathrm{dB} /$ Oct.) & $-1.6(-1.8)$ & $-2.8(-3)$ & $-4(-4.2)$ \\
\hline
\end{tabular}

Table 6. Frequency characteristics of the high-pass filter in Figure $4 \mathrm{~b}$.

\begin{tabular}{cccc}
\hline Parameter & $\boldsymbol{\alpha}=\mathbf{0 . 3}$ & $\boldsymbol{\alpha}=\mathbf{0 . 5}$ & $\boldsymbol{\alpha}=\mathbf{0 . 7}$ \\
\hline$f_{h, h p}(\mathrm{~Hz})$ & $143(145)$ & $36.4(37.3)$ & $18.2(18.7)$ \\
phase @ $f_{h, h p}(\mathrm{deg})$ & $8(8.3)$ & $14.7(15)$ & $23.9(23.9)$ \\
slope (dB/Oct.) & $1.7(1.8)$ & $2.9(3)$ & $4.1(4.2)$ \\
\hline
\end{tabular}

The electronic tuning capability of the filters for $\alpha=0.5$ is demonstrated in Figure 11, where for bias currents $\{5,10,15\} \mathrm{nA}$, for the low-pass filter the corresponding half-power frequencies were $\{0.77,2.6,5.7\} \mathrm{Hz}$, while for the high-pass filter the derived half-power frequencies were $\{9.4,36.4,80\} \mathrm{Hz}$. These results are close to the results $\{0.68,2.7,6.1\} \mathrm{Hz}$ and $\{9.3,37.3,83.9\} \mathrm{Hz}$, which are derived according to (30).

The sensitivity behavior of the filters has been evaluated using the Monte Carlo analysis tool ( $N=100$ runs) and the derived values of standard deviation of the half-power frequency 
were $\{0.004,0.01,0.01\} \mathrm{Hz}$ for the low-pass filter and $\{0.6,0.17,0.05\} \mathrm{Hz}$ for the high-pass filter. The obtained statistical plots for order $\alpha=0.5$ are provided in Figure 12.

Performing also a sensitivity analysis, the obtained results showed that for the low-pass filter topology in Figure 4a, the obtained error in the measurement of the half-power frequency is caused by Mn1, while transistors Mn1 and Mn2 equally contribute in the error of the low frequency gain. In the case of the high-pass filter circuit of Figure $4 \mathrm{~b}$, transistors Mp1 and Mp2 equally contribute to the derived deviations in the measurement of the half-power frequency as well as of the high frequency gain.

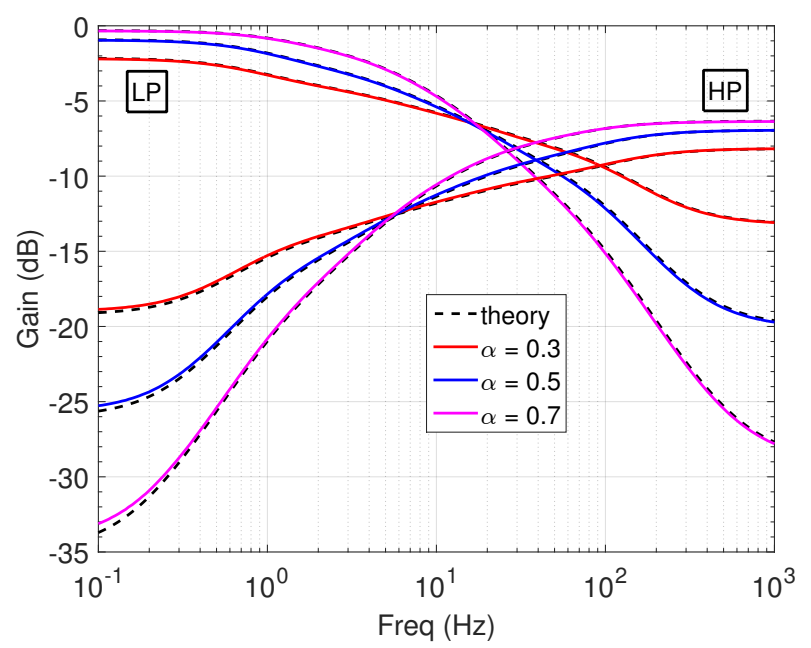

(a)

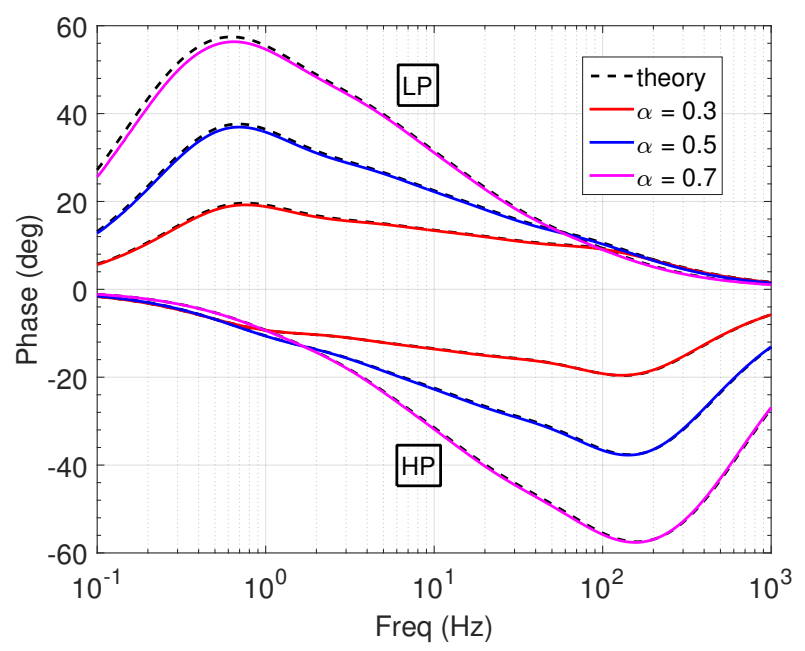

(b)

Figure 10. Simulated frequency responses of the proposed current-mode low-pass (Figure 4a) and high-pass (Figure 4 b) filters (a) gain, and (b) phase. 


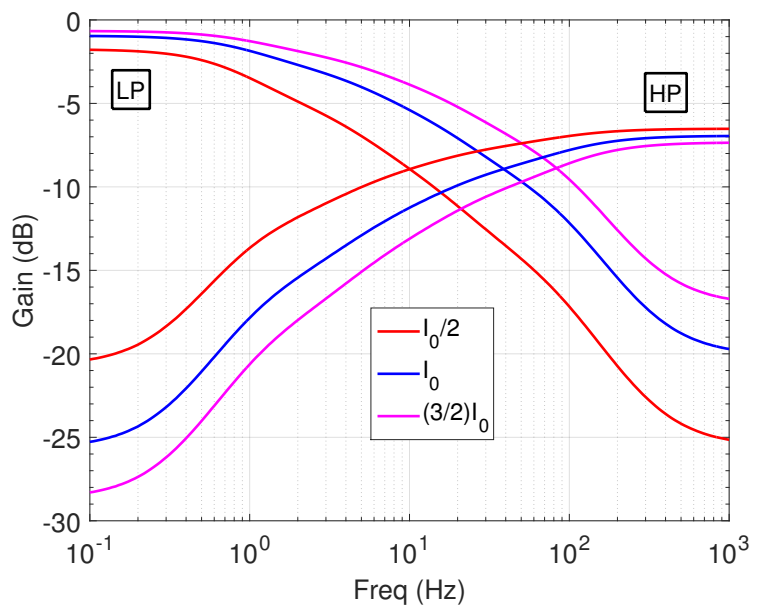

Figure 11. Demonstration of the electronic tuning capability of the current-mode low-pass and high-pass filters.

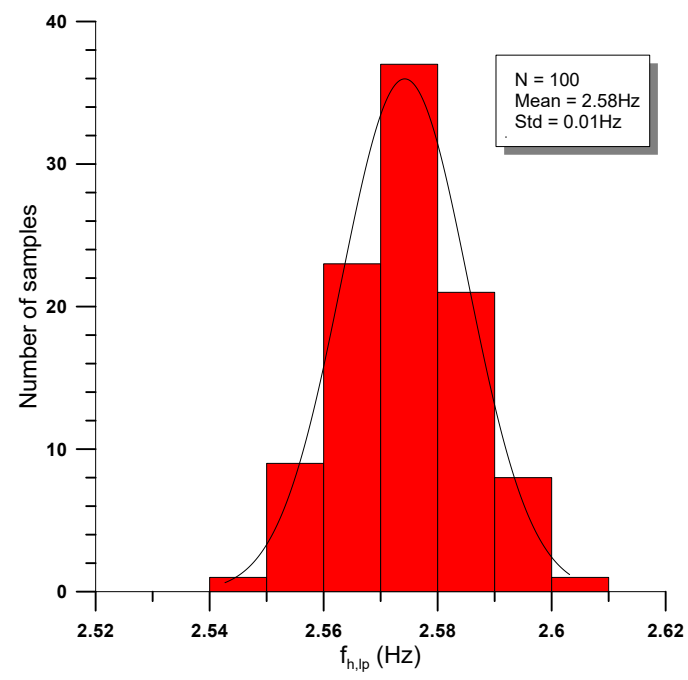

(a)

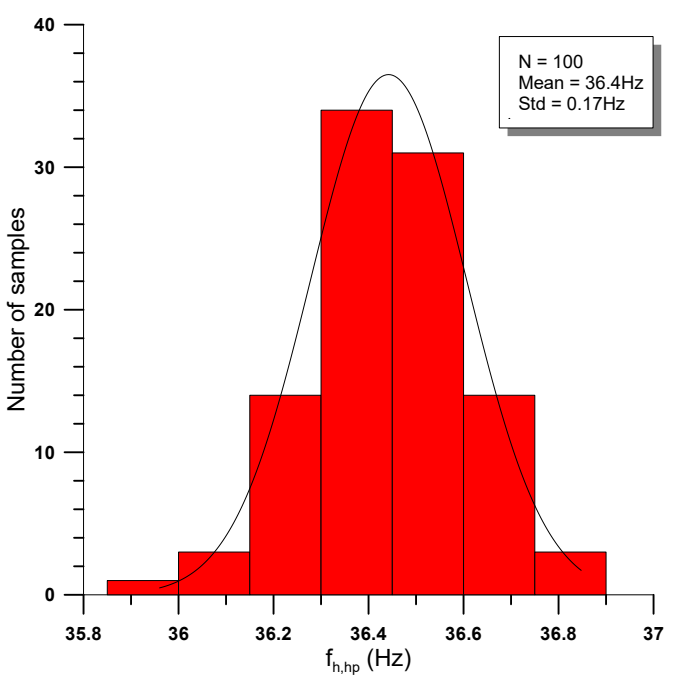

(b)

Figure 12. Statistical plots about the sensitivity of the half-power frequency in the case of the current-mode (a) low-pass, and (b) high-pass filters of order $\alpha=0.5$. 
The frequency responses of band-pass filter functions that correspond to orders $(\alpha, \beta)$ equal to $\{(0.5,0.7),(0.5,0.5),(1,0.5)\}$ are presented in Figure 13 , while the corresponding simulated values of the most important characteristics are given in Table 7.

Table 7. Frequency characteristics of the current-mode band-pass filter.

\begin{tabular}{cccc}
\hline Parameter & $(\mathbf{0 . 5}, \mathbf{0 . 7})$ & $(\mathbf{0 . 5}, \mathbf{0 . 5})$ & $(\mathbf{1}, \mathbf{0 . 5})$ \\
\hline$f_{\text {peak }}(\mathrm{Hz})$ & $9.2(9.4)$ & $9.8(10)$ & $9(9.2)$ \\
gain@ $f_{\text {peak }}(\mathrm{dB})$ & $-12.7(-12.7)$ & $-13.7(-13.7)$ & $-10.9(-10.8)$ \\
$f_{\text {low }}(\mathrm{Hz})$ & $1.7(1.9)$ & $1.4(1.5)$ & $4(4.1)$ \\
$f_{\text {high }}(\mathrm{Hz})$ & $33(35.5)$ & $62(66)$ & $29.3(31.6)$ \\
\hline
\end{tabular}

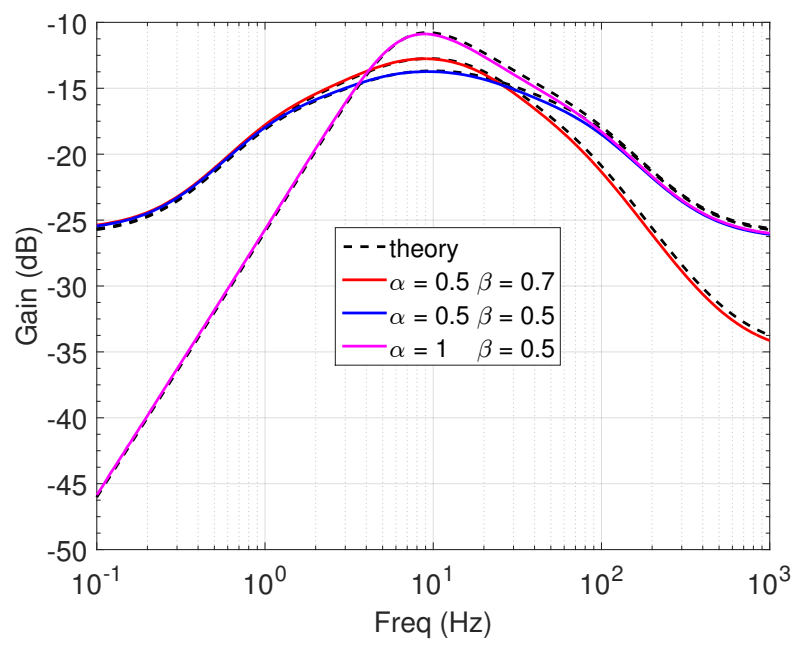

Figure 13. Frequency responses of the current mode band-pass filter for various orders.

\subsection{Comparison Results}

In order to perform a comparison between the MOS transistor count needed for implementing the OTA-C filters and the proposed structures, let us consider the typical OTA topology provided in Figure 14. Here $9 \mathrm{MOS}$ transistors are required for its implementation and the dc power dissipation, considering that $V_{D D}=-V_{S S}$, is equal to $4 V_{D D} I_{0}$.

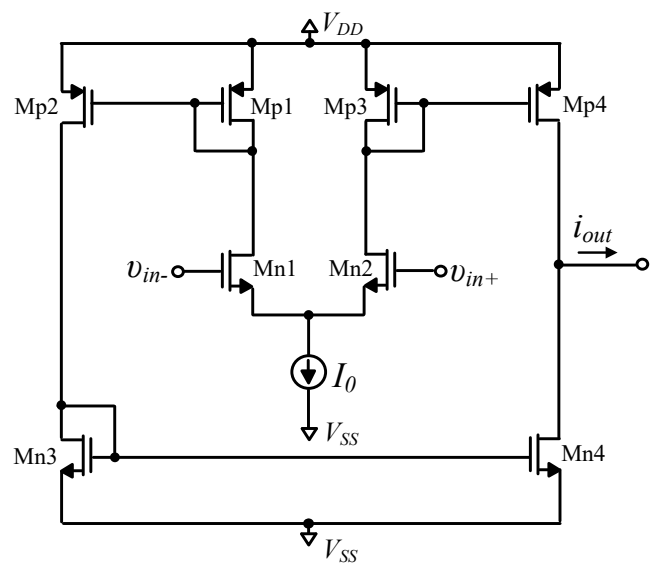

Figure 14. Typical OTA structure.

The derived comparison results between the proposed voltage-mode and current-mode filters are summarized in Tables 8 and 9, respectively. According to the provided results, it is concluded that both types of implementations offer reduced MOS transistor count, which means reduced circuit complexity, and lower dc power dissipation. 
Table 8. Comparison between the MOS transistor count and dc power dissipation for the proposed voltage-mode filters.

\begin{tabular}{ccccccc}
\hline Implementation & \multicolumn{3}{c}{ Number of Transistors } & \multicolumn{3}{c}{ Power Dissipation } \\
\hline & Low-Pass & High-Pass & Band-Pass & Low-Pass & High-Pass & Band-Pass \\
\hline OTA-C & 18 & 36 & 27 & $8 V_{D D} I_{0}$ & $16 V_{D D} I_{0}$ & $12 V_{D D} I_{0}$ \\
Proposed & 3 & 3 & 3 & $2 V_{D D} I_{0}$ & $2 V_{D D} I_{0}$ & $2 V_{D D} I_{0}$ \\
\hline
\end{tabular}

Table 9. Comparison between the MOS transistor count and dc power dissipation for the proposed current-mode filters.

\begin{tabular}{ccccccc}
\hline Implementation & \multicolumn{3}{c}{ Number of Transistors } & \multicolumn{3}{c}{ Power Dissipation } \\
\hline & Low-Pass & High-Pass & Band-Pass & Low-Pass & High-Pass & Band-Pass \\
\hline OTA-C & 18 & 18 & 27 & $8 V_{D D} I_{0}$ & $8 V_{D D} I_{0}$ & $12 V_{D D} I_{0}$ \\
Proposed & 7 & 7 & 7 & $6 V_{D D} I_{0}$ & $6 V_{D D} I_{0}$ & $6 V_{D D} I_{0}$ \\
\hline
\end{tabular}

\section{Conclusions}

The proposed voltage-mode and current-mode filter structures offer significant reduction of circuit complexity and dc power dissipation, with regards to their OTA-C counterparts. In the case of voltage-mode filters, the reduction in the number of transistors is $83.3 \%, 91.6 \%$, and $88.9 \%$ for low-pass, high-pass and band-pass filters, respectively. The achieved reduction of the dc power dissipation is $75 \%, 87.5 \%$, and $83.3 \%$, respectively. In the case of current-mode filters, the corresponding factors are $61.1 \%$ MOS transistor count reduction for both low-pass and high-pass filters, while for the band-pass filters, the corresponding value is $74.1 \%$. With regards to the power dissipation, the corresponding factors are $25 \%$ for both low-pass and high-pass filters, and $50 \%$ for the band-pass filter. Therefore, the proposed structures are attractive candidates for implementing fractional-order filters with low complexity and reduced power dissipation.

Author Contributions: Conceptualization, C.P., A.S.E. and B.M.; methodology, C.P. and A.S.E.; validation, P.B.; formal analysis, P.B.; investigation, C.P. and P.B.; writing-original draft preparation, C.P. and P.B.; writing-review and editing, A.S.E. and B.M.; supervision: C.P.

Funding: This research received no external funding.

Acknowledgments: This work is supported by the General Secretariat for Research and Technology (GSRT) and the Hellenic Foundation for Research and Innovation (HFRI). This article is based upon work from COST Action CA15225, a network supported by COST (European Cooperation in Science and Technology).

Conflicts of Interest: The authors declare no conflict of interest.

\section{Abbreviations}

The following abbreviations are used in this manuscript:

$\begin{array}{ll}\text { MOS } & \text { Metal-Oxide-Semiconductor } \\ \text { CMOS } & \text { Complementary Metal-Oxide-Semiconductor } \\ \text { IC } & \text { Integrated Circuit } \\ \text { RC } & \text { Resistor Capacitor } \\ \text { OP-AMP } & \text { Operational Amplifier } \\ \text { OTA } & \text { Operational Transconductance Amplifier } \\ \text { CCII } & \text { Second-generation Current Conveyor } \\ \text { CFOA } & \text { Current Feedback Operational Amplifier } \\ \text { CM } & \text { Current-Mirrors }\end{array}$




\section{References}

1. Hidalgo-Reyes, J.; Gómez-Aguilar, J.F.; Escobar-Jiménez, R.F.; Alvarado-Martínez, V.M.; López-López, M.G. Classical and fractional-order modeling of equivalent electrical circuits for supercapacitors and batteries, energy management strategies for hybrid systems and methods for the state of charge estimation: A state of the art review. Microelectron. J. 2019, 85, 109-128. [CrossRef]

2. Morales-Delgado, V.F.; Gómez-Aguilar, J.F.; Taneco-Hernández, M.A.; Escobar-Jiménez, R.F. Fractional operator without singular kernel: Applications to linear electrical circuits. Int. J. Circuit Theory Appl. 2018, 46, 2394-2419. [CrossRef]

3. Sun, H.G.; Zhang, Y.; Baleanu, D.; Chen, W.; Chen, Y.Q. A new collection of real world applications of fractional calculus in science and engineering. Commun. Nonlinear Sci. Numer. Simul. 2018, 64, $213-231$. [CrossRef]

4. Elwakil, A.S. Fractional-order circuits and systems: An emerging interdisciplinary research area. IEEE Circuits Syst. Mag. 2010, 10, 40-50. [CrossRef]

5. Tsirimokou, G.; Psychalinos, C.; Elwakil, A. Design of CMOS Analog Integrated Fractional-Order Circuits: Applications in Medicine and Biology; Springer: Berlin/Heidelberger, Germany, 2017. [CrossRef]

6. Agambayev, A.; Farhat, M.; Patole, S.P.; Hassan, A.H.; Bagci, H.; Salama, K.N. An ultra-broadband single-component fractional-order capacitor using $\mathrm{MoS}_{2}$-ferroelectric polymer composite. Appl. Phys. Lett. 2018, 113, 093505. [CrossRef]

7. Biswas, K.; Caponetto, R.; Di Pasquale, G.; Graziani, S.; Pollicino, A.; Murgano, E. Realization and characterization of carbon black based fractional order element. Microelectron. J. 2018, 82, 22-28. [CrossRef]

8. Caponetto, R.; Di Pasquale, G.; Graziani, S.; Murgano, E.; Pollicino, A. Realization of Green Fractional Order Devices by using Bacterial Cellulose. AEU Int. J. Electron. Commun. 2019, 112, 152927. [CrossRef]

9. Carlson, G.; Halijak, C. Approximation of fractional capacitors $(1 / s)^{\wedge}(1 / n)$ by a regular Newton process. IEEE Trans. Circuit Theory 1964, 11, 210-213. [CrossRef]

10. Valsa, J.; Vlach, J. RC models of a constant phase element. Int. J. Circuit Theory Appl. 2013, 41, 59-67. [CrossRef]

11. Oustaloup, A.; Levron, F.; Mathieu, B.; Nanot, F.M. Frequency-band complex noninteger differentiator: Characterization and synthesis. IEEE Trans. Circuits Syst. I Fundam. Theory Appl. 2000, 47, 25-39. [CrossRef]

12. Krishna, B. Studies on fractional order differentiators and integrators: A survey. Signal Process. 2011, 91, 386-426. [CrossRef]

13. Matsuda, K.; Fujii, H. $H_{\infty}$ optimized wave-absorbing control-Analytical and experimental results. J. Guid. Control Dyn. 1993, 16, 1146-1153. [CrossRef]

14. El-Khazali, R. On the biquadratic approximation of fractional-order Laplacian operators. Analog. Integr. Circuits Signal Process. 2015, 82, 503-517. [CrossRef]

15. AbdelAty, A.; Elwakil, A.; Radwan, A.; Psychalinos, C.; Maundy, B. Approximation of the fractional-order Laplacian $\mathrm{s}^{\alpha}$ as a weighted sum of first-order high-pass filters. IEEE Trans. Circuits Syst. II Express Briefs 2018, 65, 1114-1118. [CrossRef]

16. Tsirimokou, G.; Kartci, A.; Koton, J.; Herencsar, N.; Psychalinos, C. Comparative study of discrete component realizations of fractional-order capacitor and inductor active emulators. J. Circuits Syst. Comput. 2018, 27, 1850170. [CrossRef]

17. Adhikary, A.; Sen, S.; Biswas, K. Practical realization of tunable fractional order parallel resonator and fractional order filters. IEEE Trans. Circuits Syst. I Regul. Pap. 2016, 63, 1142-1151. [CrossRef]

18. Baxevanaki, K.; Kapoulea, S.; Psychalinos, C.; Elwakil, A.S. Electronically tunable fractional-order highpass filter for phantom electroencephalographic system model implementation. AEU Int. J. Electron. Commun. 2019, 110, 152850. [CrossRef]

19. Bertsias, P.; Psychalinos, C.; Elwakil, A.; Safari, L.; Minaei, S. Design and application examples of CMOS fractional-order differentiators and integrators. Microelectron. J. 2019, 83, 155-167. [CrossRef]

20. Bertsias, P.; Psychalinos, C.; Maundy, B.J.; Elwakil, A.S.; Radwan, A.G. Partial fraction expansion-based realizations of fractional-order differentiators and integrators using active filters. Int. J. Circuit Theory Appl. 2019, 47, 513-531. [CrossRef] 
21. Dimeas, I.; Tsirimokou, G.; Psychalinos, C.; Elwakil, A.S. Experimental verification of fractional-order filters using a reconfigurable fractional-order impedance emulator. J. Circuits Syst. Comput. 2017, 26, 1750142. [CrossRef]

22. Dvorak, J.; Langhammer, L.; Jerabek, J.; Koton, J.; Sotner, R.; Polak, J. Synthesis and Analysis of Electronically Adjustable Fractional-Order Low-Pass Filter. J. Circuits Syst. Comput. 2018, 27, 1850032. [CrossRef]

23. Freeborn, T.J.; Maundy, B.; Elwakil, A.S. Field programmable analogue array implementation of fractional step filters. IET Circuits Devices Syst. 2010, 4, 514-524. [CrossRef]

24. Jerabek, J.; Sotner, R.; Dvorak, J.; Polak, J.; Kubanek, D.; Herencsar, N.; Koton, J. Reconfigurable fractional-order filter with electronically controllable slope of attenuation, pole frequency and type of approximation. J. Circuits Syst. Comput. 2017, 26, 1750157. [CrossRef]

25. Kapoulea, S.; Psychalinos, C.; Elwakil, A.S. Single active element implementation of fractional-order differentiators and integrators. AEU Int. J. Electron. Commun. 2018, 97, 6-15. [CrossRef]

26. Kaskouta, E.; Kamilaris, T.; Sotner, R.; Jerabek, J.; Psychalinos, C. Single-Input Multiple-Output and Multiple-Input Single-Output Fractional-Order Filter Designs. In Proceedings of the 2018 41st International Conference on Telecommunications and Signal Processing (TSP), Athens, Greece, 4-6 July 2018; pp. 1-4.

27. Khateb, F.; Kubánek, D.; Tsirimokou, G.; Psychalinos, C. Fractional-order filters based on low-voltage DDCCs. Microelectron. J. 2016, 50, 50-59. [CrossRef]

28. Koton, J.; Kubanek, D.; Sladok, O.; Vrba, K.; Shadrin, A.; Ushakov, P. Fractional-Order Low-and High-Pass Filters Using UVCs. J. Circuits Syst. Comput. 2017, 26, 1750192. [CrossRef]

29. Koton, J.; Kubanek, D.; Herencsar, N.; Dvorak, J.; Psychalinos, C. Designing constant phase elements of complement order. Analog Integr. Circuits Signal Process. 2018, 97, 107-114. [CrossRef]

30. Langhammer, L.; Sotner, R.; Dvorak, J.; Domansky, O.; Jerabek, J.; Uher, J. A 1+ $\alpha$ Low-Pass Fractional-Order Frequency Filter with Adjustable Parameters. In Proceedings of the 2017 40th International Conference on Telecommunications and Signal Processing (TSP), Barcelona, Spain, 5-7 July 2017; pp. 724-729.

31. Radwan, A.G.; Soliman, A.M.; Elwakil, A.S. First-order filters generalized to the fractional domain. J. Circuits Syst. Comput. 2008, 17, 55-66. [CrossRef]

32. Said, L.A.; Ismail, S.M.; Radwan, A.G.; Madian, A.H.; El-Yazeed, M.F.A.; Soliman, A.M. On the optimization of fractional order low-pass filters. Circuits Syst. Signal Process. 2016, 35, 2017-2039. [CrossRef]

33. Sotner, R.; Jerabek, J.; Petrzela, J.; Domansky, O.; Tsirimokou, G.; Psychalinos, C. Synthesis and design of constant phase elements based on the multiplication of electronically controllable bilinear immittances in practice. AEU Int. J. Electron. Commun. 2017, 78, 98-113. [CrossRef]

34. Sotner, R.; Polak, L.; Jerabek, J.; Petrzela, J. Simple two operational transconductance amplifiers-based electronically controllable bilinear two port for fractional-order synthesis. Electron. Lett. 2018, 54, 1164-1166. [CrossRef]

35. Tsirimokou, G.; Psychalinos, C.; Elwakil, A.S.; Salama, K.N. Electronically tunable fully integrated fractional-order resonator. IEEE Trans. Circuits Syst. II Express Briefs 2018, 65, 166-170. [CrossRef]

36. Tsirimokou, G.; Psychalinos, C.; Elwakil, A.S. Fractional-order electronically controlled generalized filters. Int. J. Circuit Theory Appl. 2017, 45, 595-612. [CrossRef]

37. Mohan, P.A. VLSI Analog Filters: Active RC, OTA-C, and SC; Springer Science \& Business Media: Berlin/Heidelberger, Germany, 2012.

38. Bertsias, P.; Psychalinos, C.; Elwakil, A.; Maundy, B. Simple Multi-Function Fractional-Order Filter Designs. In Proceedings of the 2019 8th International Conference on Modern Circuits and Systems Technologies (MOCAST), Thessaloniki, Greece, 13-15 May 2019; pp. 1-4.

39. Tsirimokou, G. A systematic procedure for deriving RC networks of fractional-order elements emulators using MATLAB. AEU Int. J. Electron. Commun. 2017, 78, 7-14. [CrossRef] 
40. Vittoz, E.; Fellrath, J. CMOS analog integrated circuits based on weak inversion operation. IEEE J. Solid-State Circuits 1977, 12, 224-231. [CrossRef]

41. Enz, C.C.; Krummenacher, F.; Vittoz, E.A. An analytical MOS transistor model valid in all regions of operation and dedicated to low-voltage and low-current applications. Analog Integr. Circuits Signal Process. 1995, 8, 83-114. [CrossRef]

(C) 2019 by the authors. Licensee MDPI, Basel, Switzerland. This article is an open access article distributed under the terms and conditions of the Creative Commons Attribution (CC BY) license (http:/ / creativecommons.org/licenses/by/4.0/). 